
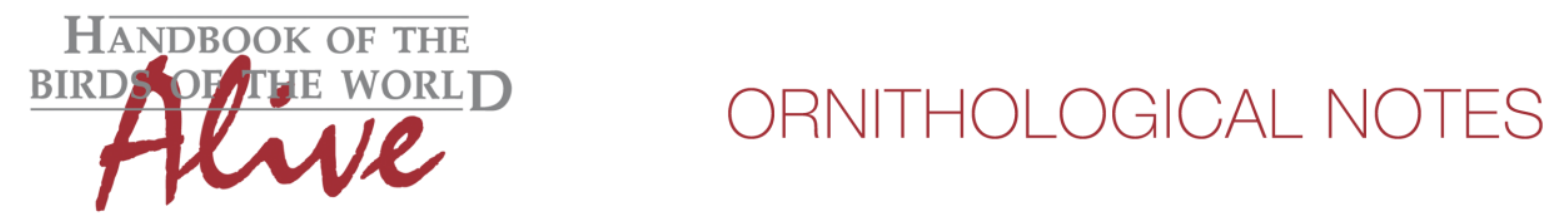

\title{
Notes on the vocalizations of Northern Scrub-flycatcher (Sublegatus arenarum), Amazonian Scrub-flycatcher (Sublegatus obscurior) and Southern Scrub-flycatcher (Sublegatus modestus)
}

Peter Boesman

In the following we briefly analyze and compare voice of the different races of Northern Scrubflycatcher (Sublegatus arenarum), Amazonian Scrub-flycatcher (Sublegatus obscurior) and Southern Scrub-flycatcher (Sublegatus modestus). We also try to quantify the extent of any vocal differences using the criteria proposed by Tobias et al. (2010), as a support for taxonomic review. We have made use of sound recordings available on-line from Xeno Canto (XC) and Macaulay Library (ML).

Formerly considered one single species, all recent taxonomies recognize three distinct Sublegatus species, although there seems to be little or no published research that supports this: Northern Scrub Flycatcher S. arenarum, Amazonian Scrub Flycatcher S. obscurior and Southern Scrub Flycatcher S. modestus.

There has been some debate where taxon orinocensis belongs, but typically it is included in S. arenarum.

S. arenarum and S. obscurior are not very vocal, as a consequence there are not many recordings available of these species.

All three (currently recognized) species have a typical dawn song, and at least one day-time call note. S. arenarum seems to have the most extensive day-time vocabulary. There are also quick note successions, typically of very excited birds. We have compared these voices, except for the latter.

\section{Dawn song}

The dawn song of Sublegatus members consists of 2 phrases which are repeated intermittently with fairly long pauses in between, e.g. ABABAB.. or AABAAABABAAB.. etc.

There are very few recordings of S. arenarum and S. obscurior (too few for a statistical analysis), but the existing recordings coincide in the following:

S. arenarum (glaber): two simple phrases, one is a bisyllabic 'wee-eew' (min. freq. $2000 \mathrm{~Hz}$, max. freq. $4000 \mathrm{~Hz}$, length $0.34 \mathrm{~s}$ ) with max. amplitude in the center, the other is a bisyllabic 'tseeweeh!' (min. freq. $2000 \mathrm{~Hz}$, max. freq. $4600 \mathrm{~Hz}$, length $0.33 \mathrm{~s}$ ) with max. amplitude towards the end:

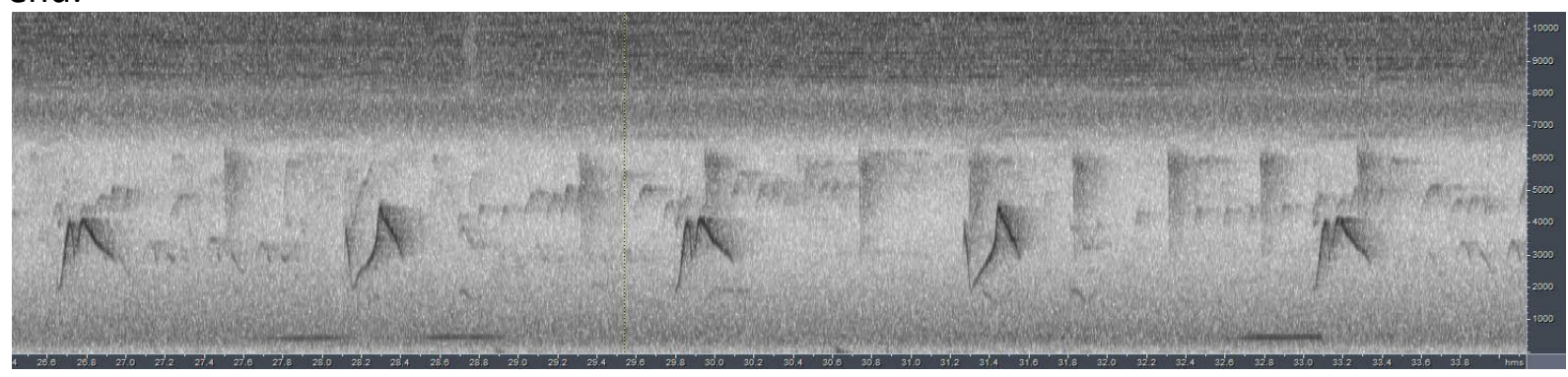



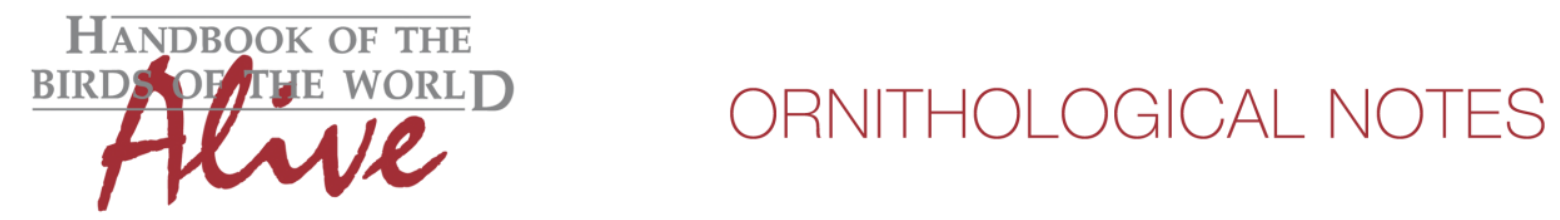

S. obscurior: two simple phrases, one is a slightly plaintive underslurred 'tseeeet' (min. freq. $3000 \mathrm{~Hz}$, max. freq. $5000 \mathrm{~Hz}$, length $0.34 \mathrm{~s}$ ) with max amplitude in the beginning, the other is a double-noted 'chee-weeh!' (min. freq. $2100 \mathrm{~Hz}$, max. freq. $5000 \mathrm{~Hz}$, length 0.33 ) with max. amplitude at $1 / 3$ of the second note (equivalent to the centre of the phrase).

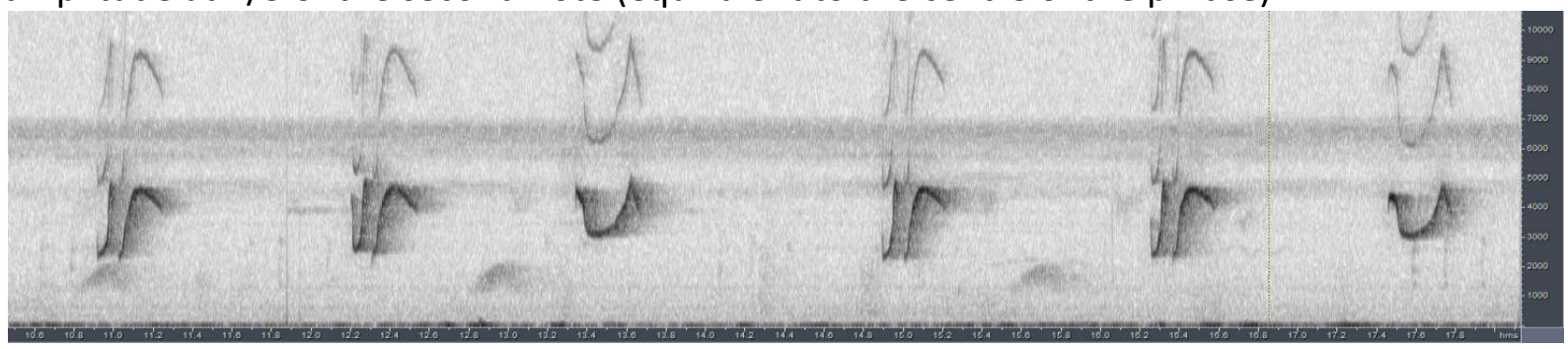

S. modestus (brevirostris): two phrases which are far more complex than previous two species, and which can be transcribed as 'tsee-tsee-leweet!' (min. freq. $2000 \mathrm{~Hz}$, max. freq. $6500 \mathrm{~Hz}$, length $0.55 \mathrm{~s}$, max. amplitude on last syllable) and 'tswee-tsew' (min. freq. $1500 \mathrm{~Hz}$, max. freq. $5900 \mathrm{~Hz}$, length $0.31 \mathrm{~s}$, max. amplitude on both notes).

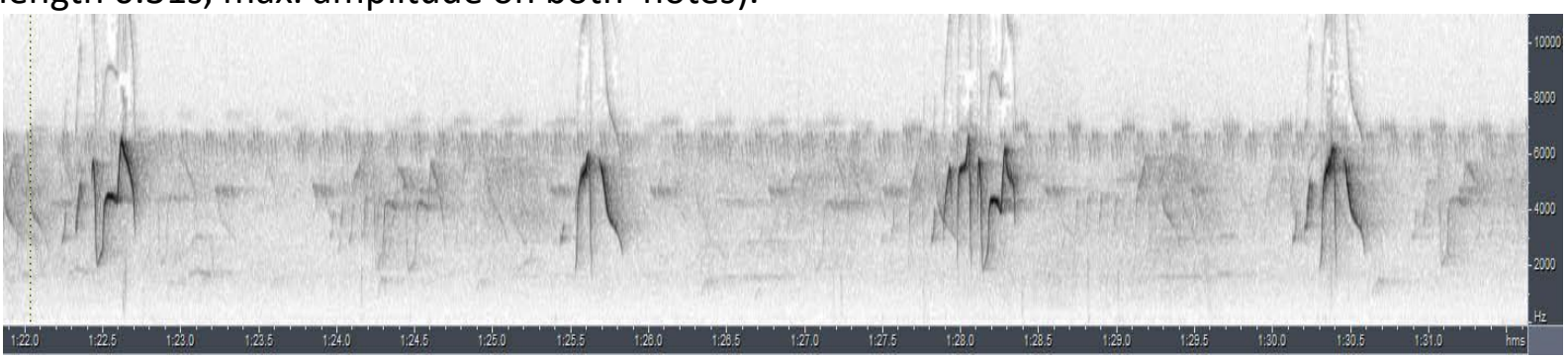

The following scores could be given for vocal differences:

S. modestus: Dawn song has clearly a higher 'number of note elements per phrase' (score 4), a longer 'length of longest phrase' (score 3), and a higher 'max. frequency' (score 3; all scores vs. both other species)

S. obscurior (vs. S. arenarum): 'Max. frequency' is higher in obscurior (score 2) and has bisyllabic notes vs. double and single notes (but barely audible) (score 1-2).

\section{Day-time calls}

S. arenarum: Unlike the other two species, several calls have been recorded, although most seem to be 'related variants', ranging from (rarely) a single overslurred whistle to a bisyllabic whistle to two separate overslurred notes. (This is valid for S.a. glaber, but also (based on few samples) for S.a. arenarum, pallens and orinocensis, no samples for the island races atrirostris and tortuguensis).

Min freq. $2500 \mathrm{~Hz}$, max. freq. $4400 \mathrm{~Hz}$, length $0.25 \mathrm{~s}$, max. amplitude on highest frequency:
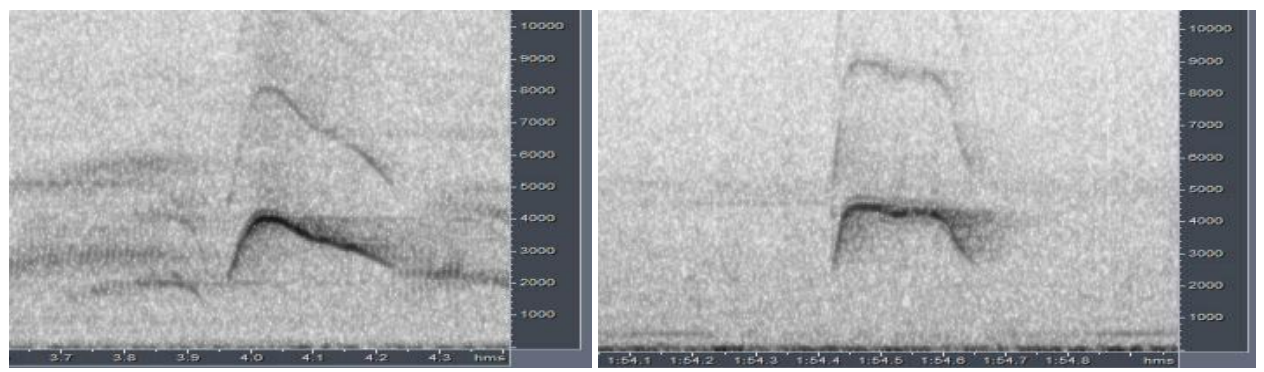


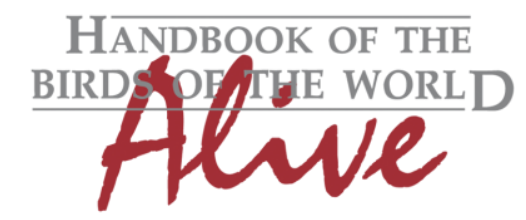

\section{ORNITHOLOGICAL NOTES}
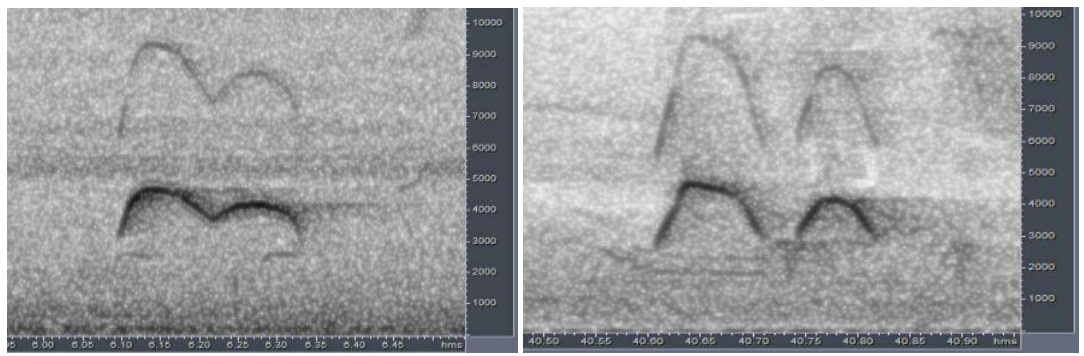

S. obscurior: The c. 10 recordings available all are of a (usually slightly burry) descending call note 'pzzeeew', occasionally preceded by a single note 'pee-pzzeeew', possibly when excited. Single call note: min. freq. $2800 \mathrm{~Hz}$, max.freq. $4750 \mathrm{~Hz}$, length $0.40 \mathrm{~s}$, max. amplitude in the first $1 / 4$ length:
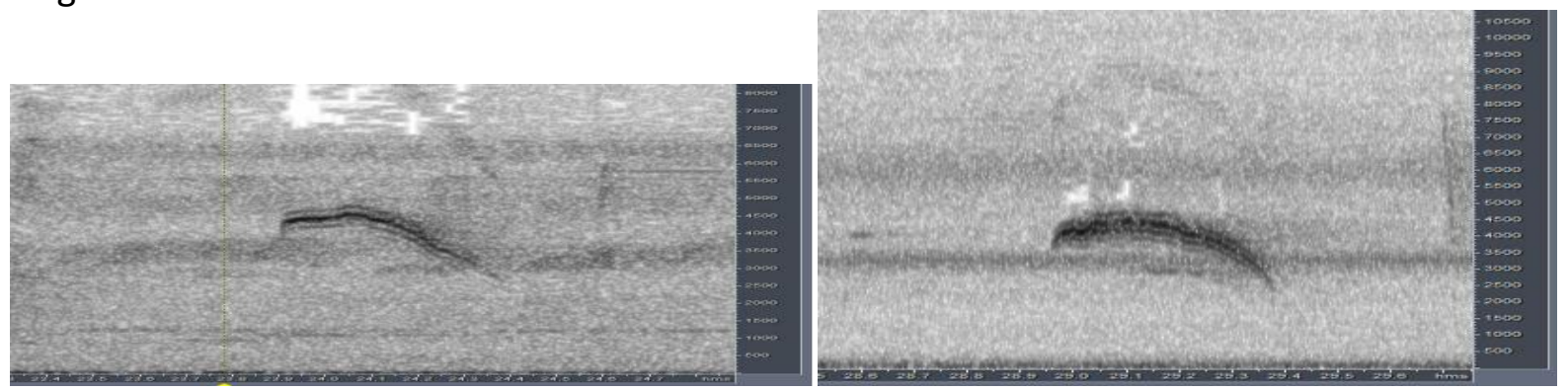

S. modestus: Almost all of the available recordings (approx. 30) are of the same type of call note, indicating this may be the only one commonly used: a short overslurred whistle 'pseeew!', with a distinct frequency peak in the middle of the note (when excited with faint introductory notes). Min. freq. $3200 \mathrm{~Hz}$, max. freq. $6200 \mathrm{~Hz}$, length. $0.25 \mathrm{~s}$, max. amplitude at approx. $1 / 3$ of note length(both S.m.modestus and S.m. brevirostris):

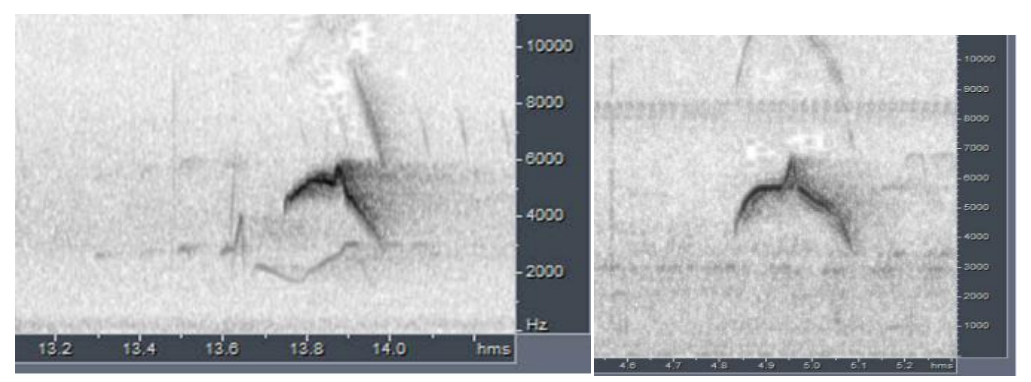

The following scores could be given for vocal differences:

S. modestus reaches a 'Max. frequency' considerable higher due to central peak (score 3), and 'Note length' is shorter vs. obscurior (score 3).

S. obscurior (vs. S. arenarum) has a longer 'Note length' (even vs. double note of arenarum) (score 3 ) and seems to have a smalelr vocabulary (score 1-2). 

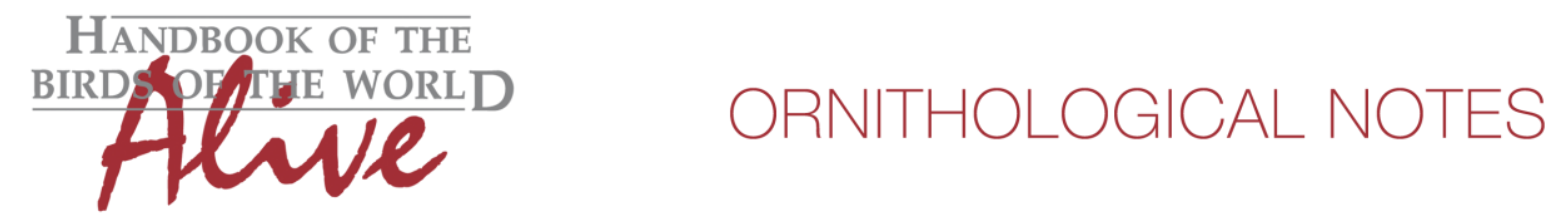

\section{In summary:}

\section{S. arenarum}

Dawn song, a long series of two phrases repeated intermittently, differs from obscurior in lower max. frequency (score 2), notes/phrase and general pattern. Day-time calls cover a continuum from a single overslurred whistle to a bisyllabic whistle to two overslurred notes. Main differences with obscurior are shorter note length (score 3 ) and vocabulary range.

\section{S. obscurior}

Dawn song, a long series of two phrases repeated intermittently, differs from arenarum in higher max. frequency (score 2), notes/phrase and general pattern. Day-time call is a single descending note, with an initial burry quality, longer than arenarum (score 3 ) and much less variable.

\section{S. modestus}

Dawn song, a long series of two phrases repeated intermittently, differs from both arenarum and obscurior in much higher complexity (number of note elements per phrase or length of longest phrase: score 4 and higher frequency: score 3). Day time call is a short overslurred whistle with a distinct frequency peak halfway (higher frequency: score 3) and shorter note length vs. obscurior.

This note was finalized on 27th March 2015, using sound recordings available on-line at that moment. We would like to thank in particular the many sound recordists who placed their recordings for this species on XC and ML.

\section{References}

Tobias, J.A., Seddon, N., Spottiswoode, C.N., Pilgrim, J.D., Fishpool, L.D.C. \& Collar, N.J. (2010). Quantitative criteria for species delimitation. Ibis 152(4): 724-746.

\section{Recommended citation}

Boesman, P. (2016). Notes on the vocalizations of Northern Scrub-flycatcher (Sublegatus arenarum), Amazonian Scrub-flycatcher (Sublegatus obscurior) and Southern Scrub-flycatcher (Sublegatus modestus). HBW Alive Ornithological Note 145. In: Handbook of the Birds of the World Alive. Lynx Edicions, Barcelona. (retrieved from http://www.hbw.com/node/932070 on 16 August 2016). 